\title{
O ENVOLVIMENTO DO SISTEMA RENINA-ANGIOTENSINA NAS DISFUNÇÕES CARDIOVASCULARES E SEUS RECURSOS FARMACOLÓGICOS
}

\section{ARTIGO DE REVISÃO}

SILVA, Thiago Fernandes da ${ }^{1}$

VAZ, Tânia Maria ${ }^{2}$

SOUZA, Miguel Soares de ${ }^{3}$

FERREIRA, Lívia Penna ${ }^{4}$

FILHO, Marcelo Limborço ${ }^{5}$

FONTES, Marco Antonio Peliky ${ }^{6}$

${ }^{1}$ Graduando em Biomedicina da Faculdade de São Lourenço - UNISEPE.

${ }^{2}$ Graduanda em Biomedicina da Faculdade de São Lourenço - UNISEPE.

${ }^{3}$ Graduando em Biomedicina da Faculdade de São Lourenço - UNISEPE.

${ }^{4}$ Farmacêutica, Bioquímica, Docente da Faculdade de São Lourenço - UNISEPE.

${ }^{5}$ Biólogo, mestre e doutor em Fisiologia e Farmacologia UFMG, Professor da Faculdade de São Lourenço - UNISEPE.

${ }^{6}$ Fisioterapeuta, mestre e doutor em Fisiologia e Farmacologia UFMG, Professor Associado do Depto. de Fisiologia \& Biofísica do Instituto de Ciências Biológicas da Universidade Federal de Minas Gerais e Pesquisador nível " 1B " do CNPq. É Membro da Sociedade Brasileira de Fisiologia e Regular Member da American Physiological Society. Com Pós-doutorado na área de Neurociência Cardiovascular na University of Sydney, Austrália. 
MARINS, Fernanda Ribeiro ${ }^{7}$

SILVA, Thiago Fernandes da. Et al. 0 envolvimento do sistema ReninaAngiotensina nas disfunções cardiovasculares e seus recursos farmacológicos. Revista Científica Multidisciplinar Núcleo do Conhecimento. Ano 04, Ed. 11, Vol. 02, pp. 181-196. Novembro de 2019. ISSN: 2448-0959, Link de acesso: https://www.nucleodoconhecimento.com.br/saude/renina-angiotensina

\section{RESUMO}

O sistema renina-angiotensina (SRA) desempenha importante função na regulação da pressão arterial e na homeostasia do organismo. Porém, em determinadas condições, a hiperatividade do SRA colabora para a gênese de diversas doenças cardiovasculares, como aterosclerose, insuficiência cardíaca e infarto do miocárdio. Para atenuação de seus efeitos prejudiciais alternativas terapêuticas foram desenvolvidas com a finalidade de modular suas ações através da interferência seletiva sobre seus componentes ou em associações medicamentosas. Nos últimos anos, a descoberta de um novo eixo do SRA capaz de produzir efeitos opostos ao clássico possibilitou a análise de novas estratégias com alto potencial terapêutico. Estudos recentes sugerem que a estimulação deste novo eixo do sistema, pode contrabalancear os efeitos deletérios da via clássica. Nesta revisão será realizada uma breve explanação do sistema renina-angiotensina e serão abordadas as diferentes terapias, existentes e em fase experimental, para o tratamento das principais doenças cardiovasculares.

Palavras-Chave: Sistema renina-angiotensina (SRA), Angiotensina II (Ang II), Angiotensina-(1-7) [Ang-(1-7)], Inibidores daenzima conversora de angiotensina (IECA), Antagonistas dos receptores $\mathrm{AT}_{1}$ da angiotensina II (ARA II).

\footnotetext{
${ }^{7}$ Fisioterapeuta, Mestre e Doutora em Fisiologia e Farmacologia UFMG, Docente da Faculdade de São Lourenço - UNISEPE.
} 


\section{INTRODUÇÃO}

Elemento crucial na regulação fisiológica e patológica das funções cardíacas, vasculares e renais ${ }^{1,2}$, o sistema renina-angiotensina (SRA) está envolvido no controle da pressão arterial e homeostase do corpo humano ${ }^{3,4}$.

Em resposta à hipotensão, ao aumento da atividade simpática e às alterações na concentração de cloreto de sódio ( $\mathrm{NaCl}$ ) vascular, o SRA é ativado, desencadeando uma sequência de ações consistentes, inicialmente culminando com a liberação da renina $^{5,6}$

Por sua vez, a renina, enzima proteolítica, é produzida e armazenada pelas células justaglomerulares do rim $^{5}$, e secretada na corrente sanguínea com a função de converter o angiotensinogênio, uma alfa-2-globulina sintetizada principalmente no fígado, em angiotensina I (Ang I), um decapeptídeo pró-hormônio inativo ${ }^{7}$. Este, sob influência da enzima conversora de angiotensina (ECA), uma protease encontrada, sobretudo nas células endoteliais vasculares do pulmão, que cliva dois aminoácidos de sua extremidade, formando assim a angiotensina II (Ang II), um octapeptídeo fisiologicamente ativo ${ }^{8}$.

A Ang II, principal componente circulante gerado a partir do eixo tradicional do SRA, promove ações localmente, em nível de tecido, ou por meio do transporte de seus componentes na corrente sanguínea ${ }^{4,7,9}$.Tais ações, em sua maioria, são intermediadas pela ativação do receptor de Ang II do tipo $1\left(A T_{1} R\right)$, envolvido em respostas vasoconstritoras, pró-oxidantes e pró-inflamatórias, e receptor do tipo 2 $\left(A T_{2} R\right)$, que desempenha ações antagônicas se comparadas ao $A T_{1} R^{8,10,11}$.

Em condições de hiperatividade, o SRA contribui significativamente para uma série de eventos prejudiciais aos rins, vasos e coração, associados principalmente ao infarto do miocárdio, hipertrofia cardíaca, aterosclerose e insuficiênciacardíaca ${ }^{5,12}$.

Estudos realizados nas últimas décadas indicam a descoberta de uma nova via de sinalização envolvida na ativação do SRA $A^{8,11,13}$, capaz de hidrolisar a Ang I e Ang II a 
partir da enzima conversora de angiotensina 2 (ECA 2), formando um heptapeptídeo vasoativo, a angiotensina-(1-7) [Ang-(1-7)]. Este peptídeo exerce suas ações via receptor Mas (Figura 1), desempenhando um papel fundamental que contrapõe muitos efeitos da Ang II ${ }^{1,14}$, induzindo, entre outras funções, vasodilatação, natriurese e diurese ${ }^{10}$.

Entre as principais estratégias terapêuticas, envolvendo o sistema reninaangiotensina no tratamento das disfunções cardiovasculares, incluem-se: os inibidores da enzima conversora de angiotensina (IECA), os antagonistas dos receptores $A T_{1}$ da angiotensina II (ARA II), e os inibidores diretos de renina $(\text { IDR })^{15,16}$ (Figura 1).

Figura 1: A cascata de funcionamento do sistema renina-angiotensina e suas interações medicamentosas. IDR, inibidor direto da renina; IECA, inibidor da enzima conversora de angiotensina; ECA e ECA 2, enzima conversora de angiotensina; ARA II, antagonista do receptor $A T_{1}$ da angiotensina II; e $A T_{1}$ e $A T_{2}$, subtipos de receptores da angiotensina II. O símbolo vermelho indica inibição e o símbolo em verde estimulação.

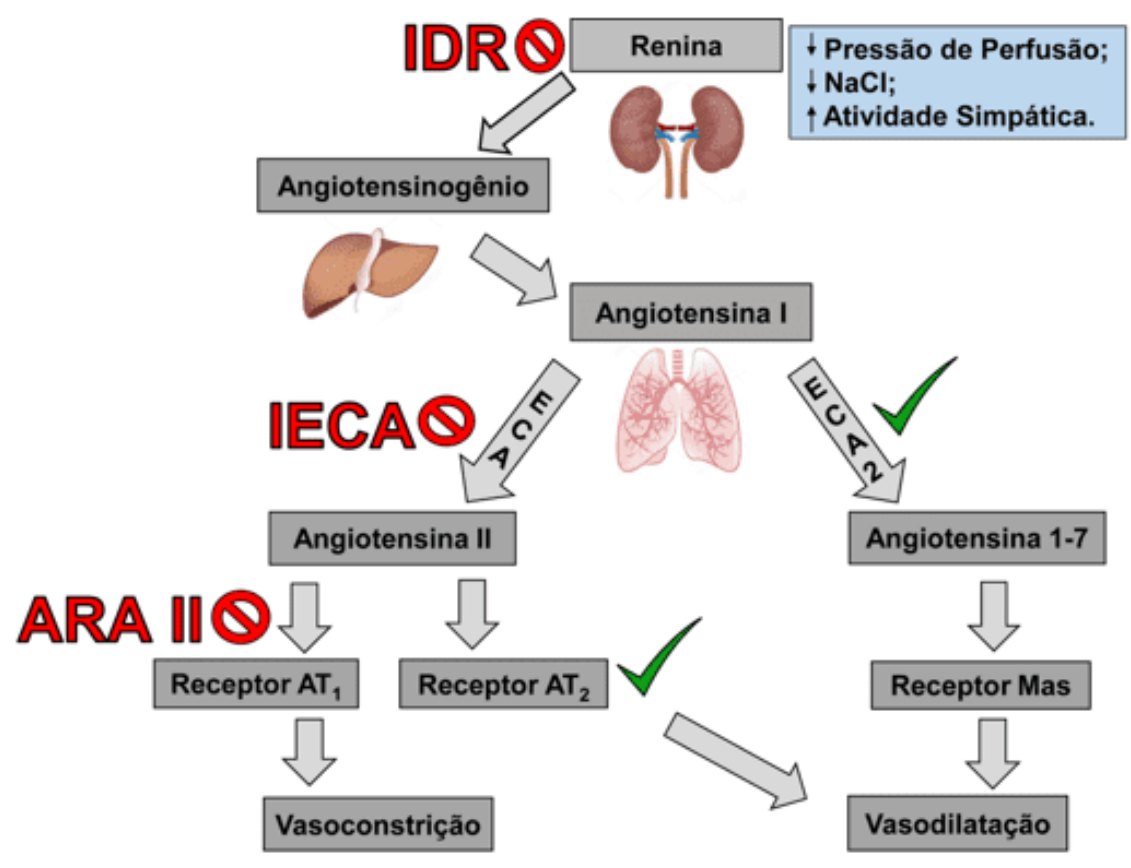


Sabendo da importância do SRA nos distúrbios ligados ao sistema cardiovascular, bem como de seus componentes serem alvos nos principais tratamentos clínicos e protocolos medicamentosos de pacientes com disfunções cardiovasculares, torna-se necessário comparar o potencial terapêutico e os efeitos colaterais nas diferentes terapias de escolha. Sendo assim, o presente trabalho procurou revisar o papel das principais terapêuticas disponíveis na prática clínica e apontar perspectivas inovadoras para o desenvolvimento de novos medicamentos que atuem nas doenças do sistema cardiovascular por meio dos componentes do SRA.

\section{METODOLOGIA}

Foi realizada uma pesquisa bibliográfica mediante a busca eletrônica de artigos científicos indexados em quatro bases de dados (SciELO, PubMed, ResearchGate e Google Acadêmico), abrangendo publicações entre os anos de 1997 ao corrente ano de 2019, totalizando, portanto, um período de 22 anos.

O estudo compreendeu os trabalhos mais relevantes publicados originalmente na língua portuguesa e inglesa, a partir dos seguintes descritores: sistema reninaangiotensina (SRA), angiotensina II (Ang II), angiotensina-(1-7) [Ang-(1-7)], disfunções cardiovasculares, inibidores da enzima conversora de angiotensina (IECA), antagonistas dos receptores $\mathrm{AT}_{1}$ da angiotensina II (ARA II), utilizados isoladamente e/ou em combinação.

A amostra abrangeu publicações de artigos selecionados a partir da leitura prévia de seus resumos anexados, e seguiram os seguintes critérios de inclusão: I) Artigos indexados em bases de dados científicas, II) Idiomas de publicação: foram selecionados artigos em língua portuguesa e inglesa, III) Ano de publicação: foram selecionados artigos publicados entre 1997 a 2019. Foram excluídos trabalhos que abordavam apenas a correlação do SRA e doenças renais, e artigos que descreveram apenas o polimorfismo no SRA. Portanto, após pré-análise e exploração do material, foram utilizados 37 artigos científicos nesta revisão de literatura. Os resultados encontrados serão separados abaixo em dois grandes tópicos, terapias convencionais e novas terapias em desenvolvimento. 


\section{TERAPIAS CONVENCIONAIS}

As terapias convencionais atualmente disponíveis ainda envolvem o eixo clássico do sistema renina-angiotensina, utilizando os inibidores da enzima conversora de angiotensina (IECA), os antagonistas dos receptores $A T_{1}$ da angiotensina II (ARA II) e os inibidores diretos de renina (IDR).

\section{INIBIDOR DA ENZIMA CONVERSORA DE ANGIOTENSINA (IECA)}

$\mathrm{Na}$ década de 1970 foi desenvolvida a primeira classe de medicamentos antihipertensivos: os inibidores da enzima conversora de angiotensina (IECA ${ }^{17}$. Ao longo dos anos, sua utilização expandiu-se para o tratamento de diversas doenças cardiovasculares ${ }^{6,18}$

Os IECAs diferem-se em relação à sua farmacocinética, farmacodinâmica e biodisponibilidade ${ }^{8}$, classificados em três subgrupos com base na sua estrutura química como demonstra a tabela $1^{6,8}$.

Tabela 1: Subgrupos dos inibidores da enzima conversora de angiotensina.

\begin{tabular}{|l|l|}
\hline Grupo sulfidrilo & alacepril, altiopril, captopril, espirapril e zofenopril. \\
\hline $\begin{array}{l}\text { Grupo } \\
\text { carboxilato }\end{array}$ & $\begin{array}{l}\text { benazepril, cilazapril, delapril, enalapril, lisinopril, moexipril, } \\
\text { perindopril, quinapril, ramipril e trandolapril. }\end{array}$ \\
\hline $\begin{array}{l}\text { Grupo } \\
\text { fosfanato }\end{array}$ & fosinopril. \\
\hline
\end{tabular}

Fonte: Adaptado de VIJAYARAGHAVAN e DEEDWANIA (2011); HERAS e colaboradores (2012).

Esta classe de medicamentos é capaz de ligar-se competitivamente com o sítio de ação da ECA, impedindo a conversão de Ang I em Ang II,8. Durante esta inibição ocorre uma diminuição da transformação das cininas, desta forma, o nível de bradicinina se eleva ocasionando efeitos benéficos como vasodilatação e redução da formação de coágulos sanguíneos ${ }^{6}$. 
No primeiro momento, o bloqueio da enzima conversora de angiotensina leva a queda dos níveis de Ang II e elevação dos níveis de renina e Ang I devido a uma perda do mecanismo de feedback negativo ${ }^{18}$. Porém, a longo prazo, verifica-se que vias alternativas ocasionam um fenômeno de escape à ECA que induz a normalização nos níveis de Ang II, uma vez que o bloqueio pelos IECA se restringe à via clássica ${ }^{19}$.

A terapêutica com IECA possui grande aceitabilidade dentre os usuários ${ }^{17}$. Entretanto, reações adversas podem ocorrer, sendo as mais relevantes: tosse seca causada pelo aumento nos níveis de bradicinina ${ }^{17,20}$, alteração do paladar caracterizado por sabor metálico, erupções cutâneas, hipotensão, hipercaliemia e, em casos mais raros, angiodema, toxicidade hepática e insuficiência renal ${ }^{10,18}$. Sua utilização é contraindicada em indivíduos que apresentem estenose das artérias renais e durante a gravidez ${ }^{18,20}$.

Os inibidores da ECA apresentam atualmente a melhor terapêutica de escolha para as disfunções cardiovasculares ${ }^{17}$, atuando na reabilitação das funções endoteliais por meio da redução da pressão arterial e da espessura da camada íntima das artérias, reduzindo assim a possibilidade de desenvolvimento e progressão da placa aterosclerótica ${ }^{6,7,21}$. Desempenham ainda ações cardioprotetoras, proporcionando efeito antimitogênico no músculo cardíaco, dificultando a ocorrência de hipertrofia e favorecendo a cicatrização após o infarto do miocárdio ${ }^{10,22}$, portanto, possuem potencial de aumentar a sobrevida de seus usuários ${ }^{18}$.

\section{ANTAGONISTA DO RECEPTOR AT 1 DA ANGIOTENSINA II (ARA II)}

Grande parte dos efeitos prejudiciais da Ang II no organismo é mediada pelo receptor do tipo $A T_{1}\left(A T_{1} R\right)^{11}$. Neste contexto, no início dos anos 90 foram desenvolvidos os antagonistas do receptor $A T_{1}$ da Ang II (ARA II) que atuam de forma seletiva ${ }^{11,18}$. Os principais fármacos atualmente disponíveis desta classe são: azilsartan, candesartan, eprosartan, irbesartan, losartan, olmesartan, telmisartan e valsartan ${ }^{6,8,17}$.

Por meio do bloqueio ocasionado pelos ARA II, os níveis de Ang II livres se elevam, já que o receptor $\mathrm{AT}_{1}$ se encontra indisponível, resultando num desvio deste peptídeo 
para os receptores do tipo $A T_{2}{ }^{23,24}$, que produzem respostas opostas ao $A T_{1} R$, destacando-se a vasodilatação ${ }^{10}$. Desta forma, é possível que os receptores $A T_{2}$ auxiliem no efeito terapêutico dos ARA II ainda que sua função fisiopatológica não esteja completamente esclarecida ${ }^{8}$.

Estes antagonistas são uma alternativa para indivíduos intolerantes aos inibidores da ECA, já que devido sua alta seletividade não ocasionam tosse seca ${ }^{6,10}$. As principais reações adversas atribuídas aos ARA II são: hipotensão sintomática em pacientes que fazem uso de diuréticos em altas doses, hipercaliemia em portadores de doença renal, cefaleia, tontura, dor nas costas, distúrbios gastrointestinais e, raramente, hipersensibilidade cutânea, sendo contraindicados para o uso de gestantes ${ }^{10,18,20}$.

O principal efeito terapêutico dos ARA II é uma intensa vasodilatação com redução da pré e pós-carga, proporcionando baixa da tensão na parede sistólica e volume diastólico, além de melhoria na remodelação vascular ${ }^{8,10}$. Demonstram eficácia no tratamento de hipertensão arterial, insuficiência cardíaca congestiva, disfunção ventricular esquerda, pós-infarto do miocárdio e na prevenção do acidente vascular encefálico ${ }^{2,20}$.

\section{INIBIDOR DIRETO DA RENINA (IDR)}

Tendo em vista que a renina é fundamental para a síntese de Ang I e Ang II na via clássica do sistema renina-angiotensina, em teoria, seu bloqueio seria o mais eficiente para atenuação dos efeitos deletérios desse sistema no organismo ${ }^{6,16}$. Contudo, a elaboração de um inibidor direto da renina (IDR) clinicamente efetivo foi retardada pela dificuldade de se efetuar testes em modelos animais, mesmo que transgênicos, devido à alta especificidade de ligação entre a renina humana e o angiotensinogênio, bem como a complexidade de geração de uma droga farmacologicamente adequada ${ }^{16}$.

No ano de 2007 foi aprovado pela Food and Drug Administration nos Estados Unidos o uso do primeiro IDR, o aliscireno, como terapia para a hipertensão primária4,23-25. Este fármaco atua como um forte inibidor competitivo de renina impossibilitando a conversão do angiotensinogênio e, por conseguinte, descontinuando a sequência de 
eventos do $\mathrm{SRA}^{8,18}$. Ainda estão em estudos outros possíveis resultados desta inibição, como a diminuição da renina plasmática e o bloqueio de seu receptor ${ }^{20}$.

O aliscireno possui boa tolerabilidade com raras interrupções de tratamento, entretanto alguns efeitos colaterais foram relatados: diarreia, quando em superdosagem, erupção cutânea, cefaleia, nasofaringite, aumento de creatinofosfoquinase e angiodema ${ }^{16,26}$, sendo seu uso impróprio para gestantes ${ }^{20}$.

Diversas pesquisas em modelos animais ainda estão em desenvolvimento para a comprovação da eficácia do aliscireno como terapia de disfunções cardiovasculares, incluindo a progressão da placa aterosclerótica, insuficiência e remodelação cardíaca $^{2,20}$. Em ensaios clínicos de curta duração com murinos e coelhos foi encontrado efeito positivo, reduzindo a morbidade cardiovascular e hipertrofia do ventrículo esquerdo, que segundo os autores está associada à diminuição da ativação imunitária inata, do estresseoxidativo e da fibrose ${ }^{16,20}$. Outros estudos com baixas doses de aliscireno em ratos transgênicos hipertensos demonstraram uma redução na remodelação cardíaca estrutural e da atividade elétrica, levando a crer que tal fármaco apresenta efeitos intrínsecos no coração².

\section{MULTITERAPIA}

A monoterapia atual, apesar de eficiente, é limitada e apresenta falhas ${ }^{4}$. Sendo assim, foi considerada o uso da multiterapia com o objetivo de tornar o bloqueio do SRA mais satisfatório ${ }^{4,20,27}$.Um dos objetivos da combinação do IECA com ARA II é impedir a geração da Ang II por vias alternativas e assim proporcionar uma inibição mais completa sobre o SRA ${ }^{6,8}$.

Estudos relataram uma redução expressiva da pressão arterial e da mortalidade por doenças cardiovasculares através desta associação medicamentosa ${ }^{27}$. Por outro lado, foram descritos riscos de hipercaliemia, insuficiência renal crônica e hipotensão sintomática como efeitos colaterais ${ }^{8}$. Portanto, doses menores destes fármacos podem apresentar melhor equilíbrio entre o resultado terapêutico e o adverso ${ }^{18,20}$. 
Tendo em vista que o uso monoterápico de IECA e ARA II elevam a renina plasmática, a associação destes com o IDR podem apresentar - ao menos em teoria - efeitos complementares benéficos ${ }^{16}$. De acordo com Giestas e colaboradores ${ }^{18}(2010)$ o uso concomitante de tais terapias em pacientes com disfunções cardiovasculares demonstrou redução da hipertensão, hipertrofia e insuficiência cardíaca.

\section{NOVAS TERAPIAS EM DESENVOLVIMENTO}

\section{ANGIOTENSINA-(1-7) [ANG-(1-7)]}

No final da década de 1980, a descoberta da Ang-(1-7 ${ }^{28}$, um heptapeptídeo vasoativo, formada a partir da Ang II por meio da enzima conversora de angiotensina II (ECA 2) ${ }^{11,29}$, comprovou a existência de uma segunda via do sistema renina-angiotensina, capaz de equilibrar os efeitos do eixo clássico no organismo 24 .

No ano de 1986 foi identificado um receptor acoplado à proteína G denominado Mas ${ }^{30}$. Todavia, somente em 2003 elucidou-se que grande parte das ações da Ang-(1-7) são mediadas por ativação deste receptor ${ }^{14,31}$, que proporciona respostas vasodilatadoras e anti-hipertensivas capazes de contrabalancear a atividade do eixo Ang II/receptor $\mathrm{AT}_{1}{ }^{8,14}$.

Em estudos posteriores foi observado que a ligação da Ang-(1-7) ao receptor Mas ocasiona a liberação de óxido nítrico promovendo ações antiploriferativas das células do músculo liso vascular, vasodilatação ${ }^{7,14,24}$, efeitos anti-fibróticos e anti-trombóticos, desempenhando assim um papel importante nas funções cardíacas ${ }^{3,8,32}$, tornando este novo eixo um importante e potencial alvo terapêutico ${ }^{23}$.

Conforme Jiang e colaboradores ${ }^{1}$ (2014) e De Mello² (2017), o uso de Ang-(1-7) em modelos animais evitou a progressão das lesões ateroscleróticas, reduziu a ocorrência de insuficiência cardíaca após o infarto do miocárdio e aumentou a perfusão coronariana bem como a atividade endotelial da aorta. Outros resultados obtidos por De Castro ${ }^{33}$ (2008) indicaram que o eixo Ang-(1-7)/Mas apresentou 
atividade fundamental durante a isquemia facilitando a remodelação cardíaca e a modulação da função endotelial.

Experimentos efetuados em camundongos Mas knockout revelaram um aumento da resistência vascular, local e sistêmica, e redução do débito cardíaco, indicando assim um importante papel deste receptor na manutenção hemodinâmica ${ }^{13}$. Devido à capacidade de vasodilatação da Ang-(1-7), foram realizados ensaios em pacientes com pré-eclâmpsia demonstrando resultados positivos após a administração intravenosa de uma formulação de Ang-(1-7 $)^{3}$.

Sem dúvida, a utilização terapêutica da Ang-(1-7) e de fármacos que estimulem a atividade da ECA $2^{8}$, são alternativas promissoras para o tratamento das disfunções cardiovasculares por meio da regulação da pressão arterial, da recuperação da função cardíaca e endotelial ${ }^{14,31,34}$.

\section{RECEPTOR DA ANGIOTENSINA II DO TIPO 2 (AT 2 R)}

A descoberta do receptor da Ang II do tipo 2, já no início da década de 1990, contribuiu para evidenciar novos efeitos desse peptídeo além dos previamente conhecidos associados ao $A T_{1} R^{32,35}$. Este receptor é expresso de forma abundante no período fetal, tendo uma marcante redução após o nascimento ${ }^{18,24}$. Entretanto, na fase adulta, o $\mathrm{AT}_{2} \mathrm{R}$ volta a ser expresso notavelmente em alguns estados patológicos, como na insuficiência cardíaca, no infarto do miocárdio e nas lesões cerebrais e vasculares ${ }^{7}$.

Análises sugerem que o $\mathrm{AT}_{2} \mathrm{R}$ modula respostas anti-inflamatórias, antiproliferativas, antioxidantes, vasodilatadoras e neuroregenerativas que contrapõem os efeitos do $A T_{1} R^{17,26,36}$. Experimentos in vitro e in vivo propõem que a ativação do receptor $A T_{1}$ module a expressão do $\mathrm{AT}_{2}$, presumindo, assim, a existência de um mecanismo intrínseco capaz de articular os efeitos da Ang II no sistema cardiovascular ${ }^{14,37}$.

$\mathrm{O}$ uso de agonistas do receptor $\mathrm{AT}_{2}$ representa uma nova alternativa, ainda em desenvolvimento, de grande potencial terapêutico para o tratamento de diversas disfunções cardiovasculares ${ }^{7,8,14}$. 


\section{CONSIDERAÇÕES FINAIS}

O sistema renina-angiotensina (SRA), por meio de seus componentes, é capaz de gerar eventos benéficos e/ou prejudiciais ao sistema cardiovascular. Sabendo disto, foram criadas terapias utilizando IECA, ARA II e IDR com a finalidade de bloquear de forma parcial seu eixo clássico. Entretanto, por não exercerem sua eficácia de forma satisfatória em todos os pacientes ou apresentarem efeitos adversos, a busca por novas alternativas terapêuticas continua. Novos tratamentos, como a estimulação do receptor $\mathrm{AT}_{2}$ e do eixo Ang-(1-7)/Mas tornaram-se uma perspectiva promissora para o desenvolvimento de futuros medicamentos, e uma esperança para pacientes refratários às terapias existentes. Deste modo, novos estudos experimentais e ensaios clínicos são necessários para avaliar cuidadosamente as vantagens dessas terapêuticas nas disfunções cardiovasculares.

\section{REFERÊNCIAS}

1. JIANG F.; YANG, J.; ZHANG, Y.; DONG, M.; WANG, S.; ZHANG, Q. et al. Angiotensin-converting enzyme 2 and angiotensin 1-7: novel therapeutic targets. Nature Reviews Cardiology, v. 11, n. 7, p. 413-426, 2014.

2. DE MELLO, W.C. Local Renin Angiotensin Aldosterone Systems and Cardiovascular Diseases. The Medical Clinics of North America, v. 101, n. 1, p. 117127, 2017.

3. FERREIRA, A.J.; SANTOS, R.A.S. Cardiovascular actions of angiotensin-(1-7). Brazilian Journal of Medical and Biological Research, v. 38, n. 4, p. 499-507, 2005.

4. MANSUR, S.J.; HAGE, F.G.; OPARIL, S. HavetheRenin-Angiotensin-Aldosterone System Perturbations in Cardiovascular Disease Been Exhausted?.Current Cardiology Reports, v. 12, n. 6, p. 450-463, 2010.

5. BREWSTER, U.C.; SETARO, J.F.; PERAZELLA, M.A. The Renin-AngiotensinAldosterone System: Cardiorenal Effects and Implications for Renal and 
Cardiovascular Disease States. The American Journal of the Medical Sciences, v. 326, n. 1, p. 15-24, 2003.

6. VIJAYARAGHAVAN, K.; DEEDWANIA, P. Renin-Angiotensin-AldosteroneBlockade for Cardiovascular DiseasePrevention. CardiologyClinics, v. 29, n. 1, p. 137-156, 2011.

7. DURANTE, A.; PERETTO, G. LARICCHIA, A.; ANCONA, F.; SPARTERA, M.; MANGIERI, A. et al. Role of the Renin-Angiotensin-Aldosterone System in the Pathogenesis of Atherosclerosis. Current Pharmaceutical Design, v. 18, n. 7, p. 9811004, 2012.

8. HERAS, M.M.; RODRÍGUEZ, N.C.; GONZÁLEZ, J.F.N. The Renin-AngiotensinAldosterone System in Renal and Cardiovascular Disease and the Effects of its Pharmacological Blockade. Journal of Diabetes and Metabolism, v. 3, n. 1, p. 1-24, 2012.

9. ARAÚJO, M.A.; MENEZES, B.S.; LOURENÇO, C.; CORDEIRO, E.R.; GATTI, R.R.; GOULART, L.R. O gene do angiotensinogênio (m235t) e o infarto agudo do miocárdio. Revista da Associação Médica Brasileira, v. 51, n. 3, p. 164-169, 2005.

10. BORGHI, C.; ROSSI, F. Role of the Renin-Angiotensin-Aldosterone System and Its Pharmacological Inhibitors in Cardiovascular Diseases: Complex and Critical Issues. High Blood Pressure \& Cardiovascular Prevention, v. 22, n. 4, p. 429-444, 2015.

11. SANTOS, R.A.S.; OUDIT, G.Y.; VERANO-BRAGA, T.; CANTA, G.; STECKELINGS, U.M.; BADER, M. The renin-angiotensin system: going beyond the classical paradigms. American Journal of Physiology - Heart and Circulatory Physiology, v. 316, n. 5, p. 958-970, 2019.

12. ANDERSEN, S.; ANDERSEN, A.; NIELSEN-KUDSK, J.E. The renin-angiotensinaldosterone-system and right heart failure in congenital heart disease. International Journal of Cardiology: Heart \& Vasculature, v. 11, n. 2, p. 59-65, 2016. 
13. SANTOS, R.A.S. Angiotensin-(1-7). Hypertension, v. 63, n. 6, p. 1138-1147, 2014.

14. UNGER T.; STECKELINGS, U.M.; SANTOS, R.A.S. The Protective Arm of the Renin Angiotensin System (RAS): Functional Aspects and Therapeutic Implications. Reino Unido: Academic Press, 2015. 316 p.

15. FERRARIO, C.M.; STRAWN, W.B. Role of the Renin-Angiotensin-Aldosterone System and Proinflammatory Mediators in Cardiovascular Disease. The American Journal of Cardiology, v. 98, n. 1, p. 121-128, 2006.

16. RAJAGOPALAN, S.; BAKRIS, G.L.; ABRAHAM, W.T.; PITT, B.; BROOK, R.D. Complete Renin-Angiotensin-Aldosterone System (RAAS) Blockade in High-Risk: Patients Recent Insights From Renin Blockade Studies. Hypertension, v. 62, n. 3, p. 444-449, 2013.

17. FEITOSA, G.S.; CARVALHO, E.N. Sistema renina-angiotensina e insuficiência cardíaca: O uso dos antagonistas do receptor da angiotensina II. Revista Brasileira de Hipertensão, v. 7, n. 3, p. 250-254, 2000.

18. GIESTAS, A.; PALMA, I.; RAMOS, M. H. Sistema renina-angiotensina-aldosterona e sua Modulação Farmacológica. Acta Médica Portuguesa, v. 23, n. 4, p. 677-688, 2010.

19. SANTOS, R.A.S.; FAGUNDES-MOURA, C.R.; SILVA, A.C.S. Efeitos cardiovasculares e renais do sistema renina-angiotensina. Revista Brasileira de Hipertensão, v. 7, n. 3, p. 227-236, 2000.

20. SOCIEDADE BRASILEIRA DE CARDIOLOGIA. VI Diretrizes brasileiras de hipertensão. Arquivos Brasileiros de Cardiologia, v. 95(1 supl. 1), p. 1-51, 2010.

21. CÉSAR, L.A.M. Sistema renina-angiotensina-aldosterona e doença sisquêmicas. Revista Brasileira de Hipertensão, v. 7, n. 3, p. 255-260, 2000. 
22. MILL, J.G.; MILANEZ, M.C.; BUSATTO, V.C.W.; DE MORAES, A.C.; GOMES, M.G.S.Ativação da Enzima Conversora de Angiotensina no Coração após Infarto do Miocárdio e suas Repercussões no Remodelamento Ventricular. Arquivos Brasileiros de Cardiologia, v. 69, n. 2, p. 101-110, 1997.

23. SCHINDLER, C.; BRAMLAGE, P.; KIRCH, W.; FERRARIO, C.M. Role of the vasodilator peptide angiotensin-(1-7) in cardiovascular drug therapy. Vascular Health and Risk Management, v. 3, n. 1, p. 125-137, 2007.

24. SANJULIAN, A.F.; TORRES, M.R.S.G.; PAULA, L.N.; BASSAN, F.B. Eixo reninaangiotensina-aldosterona: Bases fisiológicas e fisiopatológicas. Revista Hospital Universitário Pedro Ernesto - UERJ, v. 10, n. 3, p. 20-30, 2011.

25. GISMONDI, R.; OIGMAN, W. Inibidores diretos da renina no tratamento da hipertensão arterial sistêmica. Revista Hospital Universitário Pedro Ernesto UERJ, v. 10, n. 3, p. 81-86, 2011.

26. GLUBA, A.; BANACH, M.; MIKHAILIDIS, D.P.; RYSZ, J. Genetic Determinants of Cardiovascular Disease: The Renin-Angiotensin-Aldosterone System, Paraoxonases, Endothelin-1, Nitric Oxide Synthase and Adrenergic Receptors. In Vivo, v. 23, n. 5, p. 797-812, 2009.

27. ORSBORNE, C.; CHAGGAR, P.S.; SHAW, S.M.; WILLIAMS, S.G. The reninangiotensin-aldosterone system in heart failure for the non-specialist: the past, the present and the future. Postgraduate Medical Journal, v. 93, n. 1095, p. 29-37, 2017.

28. LAUTNER, R.Q.; VILLELA, D.C.; FRAGA-SILVA, R.A.; SILVA N.; VERANOBRAGA, T.; COSTA-FRAGA, F. et al. Discovery and characterization of alamandine: a novel component of therenin-angiotensin system. Circulation Research, v. 112, n. 8, p. 1104-1111, 2013.

29. PASSOS-SILVA, D.G.; VERANO-BRAGA, T.; SANTOS, R.A.S. Angiotensin-(1-7): Beyond the cardio-renal actions. Clinical Science, v. 124, n. 7, p. 443-456, 2013. 
30. BADER, M.; ALENINA, N.; YOUNG, D.; SANTOS, R.A.S.; TOUYZ, R.M. The Meaningof Mas. Hypertension, v. 72, n. 5, p. 1072-1075, 2018.

31. SANTOS, R.A.; SIMÕES e SILVA, A.C.; MARIC, C.; SILVA, D.M.; MACHADO, R.P.; DE BUHR, I. et al. Angiotensin-(1-7) is anendogenous ligand for the G proteincoupled receptor Mas. Proceedings of the National Academy of Sciences, v. 100, n. 14, p. 8258-8263, 2003.

32. RIGATTO, K.V.; BÖHLKE, M.; IRIGOYEN, M.C. Sistema renina angiotensina: da fisiologia ao tratamento. Revista da Sociedade de Cardiologia do Rio Grande do Sul, v. 13, n. 3, p. 1-5,2004.

33. DE CASTRO, C.H. Avaliação dos efeitos da angiotensina-(1-7) e do seu receptor Mas no controle da função cardíaca utilizando animais geneticamente modificados. Belo Horizonte. Universidade Federal de Minas Gerais; 2008.

34. SANTOS, R.A.S.; SAMPAIO W.O.; ALZAMORA, A.C.; MOTTA-SANTOS, D.; ALENINA, N.; BADER, M. et al. The ACE2/Angiotensin-(1-7)/MAS Axis of the ReninAngiotensin System: Focus on Angiotensin-(1-7). Physiological Reviews, v. 98, n. 1, p. 505-553, 2018.

35. DOSTAL, D.E.; BAKER, K.M. The Cardiac Renin-Angiotensin System Conceptual, or a Regulator of Cardiac Function?. Circulation Research, v. 85, n. 7, p. 643-650, 1999.

36. TE RIET, L.; VAN ESCH, J.H.; ROKS, A.J.; VAN DEN MEIRACKER, A.H.; DANSER, A.H. Hypertension: Renin-Angiotensin-Aldosterone System Alterations. Circulation Research, v. 116, n. 6, p. 960-975, 2015.

37. CUNHA, R.S.; FERREIRA, A.V.L. Sistema renina-angiotensina-aldosterona e lesão vascular hipertensiva. Revista Brasileira de Hipertensão, v. 7, n. 3, p. 282292, 2000. 


\section{ANEXO}

Figure in English

Figure 1: The functioning cascade of the renin-angiotensin system and its drug interactions. $\mathrm{DRI}$, direct renin inhibitor; $\mathrm{ACEl}$, angiotensin converting enzyme inhibitor; $A C E$ and $A C E$ 2, angiotensin converting enzyme; $A R B$, angiotensin II $A T_{1}$ receptor blocker; $A T_{1}$ and $A T_{2}$, angiotensin II receptor subtypes type 1 and type 2 , respectively. The red symbol indicates inhibition and the green stimulation of each component.

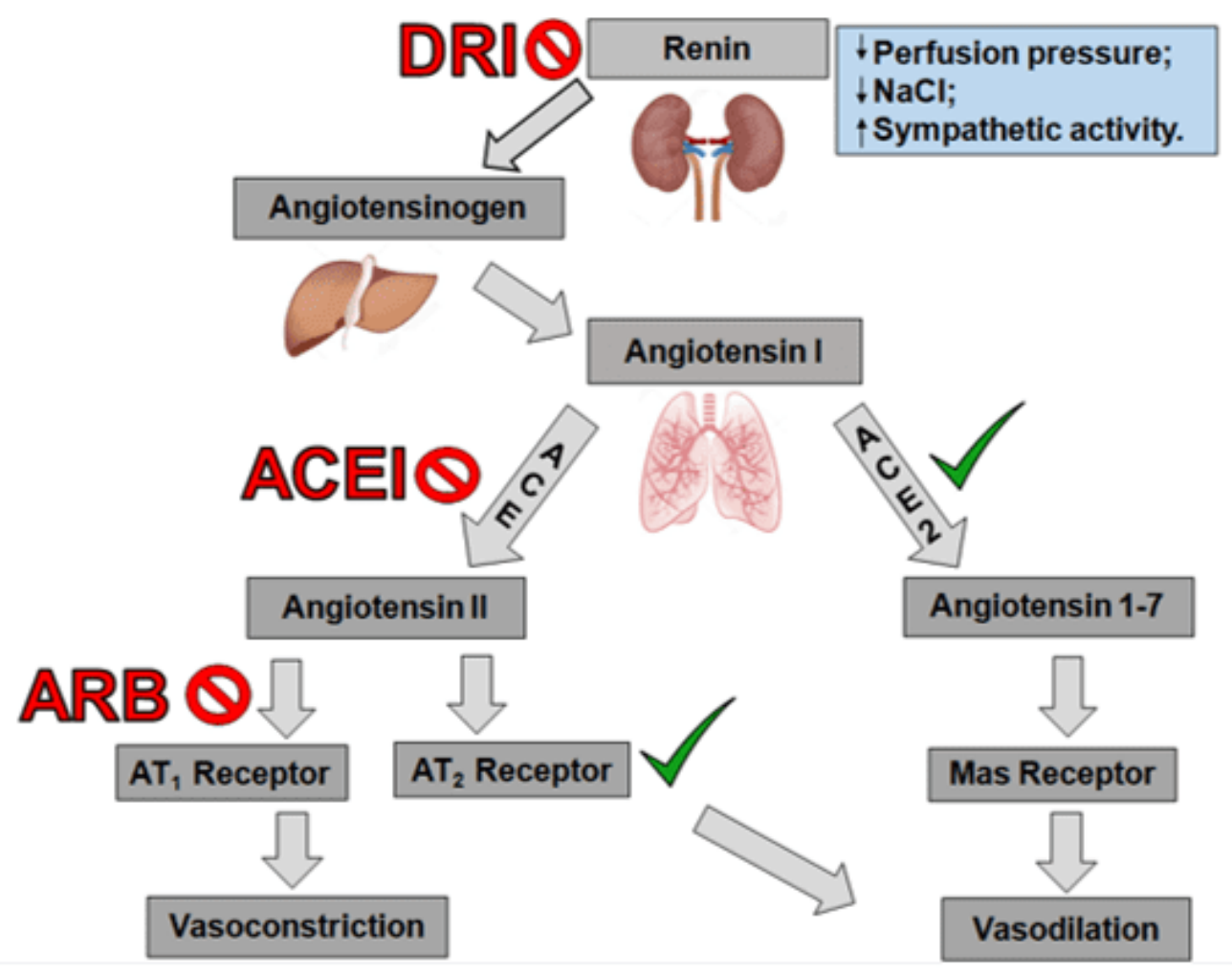

Enviado: Novembro, 2019.

Aprovado: Novembro, 2019. 